\title{
PESCA PREDATÓRIA DO MAPARÁ (Hypophthalmus spp.) NO MUNICÍPIO DE LIMOEIRO DO AJURU (PA) E EDUCAÇÃO AMBIENTAL COMO INSTRUMENTO MEDIADOR DE INTERESSES E CONFLITOS
}

Antônio Rodrigues da Silva Júnior ${ }^{1}$ Suzi Carolina Moraes Rodrigues ${ }^{2}$ André Cutrim Carvalho ${ }^{3}$

Resumo: Os peixes das espécies Hypophthalmus $H$. marginatus, $H$. edentatus e H. fimbriatus, popularmente conhecidos como Mapará, é uma importante fonte econômica e alimentar da população do município de Limoeiro do Ajuru/PA. Todavia, ações antrópicas degradadoras, relacionadas à utilização de petrechos de pesca predatória, como redes impróprias para o pescado, bem como o desrespeito ao período reprodutivo das espécies, estão provocando uma redução no estoque pesqueiro do Mapará, o que acende um sinal de alerta às autoridades e sociedade organizada que precisam instrumentar mecanismos de governança para minimizar ou mitigar essas ações antagônicas à sustentabilidade.

Palavras-chave: Ictiofauna; Implicações Socioambientais; Sensibilização Ambiental.

\footnotetext{
${ }^{1}$ Doutorando em Geografia pelo Programa de Pós-graduação em Geografia da Universidade Federal do Pará. E-mail: silvajuniorgeo@yahoo.com.br

2 Mestranda pelo Programa de Pós-graduação em Gestão dos Recursos Naturais e Desenvolvimento Local na Amazônia do Núcleo de Meio Ambiente da Universidade Federal do Pará. E-mail: suzibio12@hotmail.com

3 Pós-Doutor em Economia e Docente do Pós-graduação em Gestão dos Recursos Naturais e Desenvolvimento Local na Amazônia do Núcleo de Meio Ambiente Universidade Federal do Pará. E-mail: andrecc83@gmail.com
} 


\section{Introdução}

Os peixes das espécies Hypophthalmus: $H$. marginatus, $H$. edentatus e $H$. fimbriatus, popularmente conhecidos como Mapará, é considerado uma das principais bases alimentares da população ribeirinha do rio Tocantins, na bacia hidrográfica Tocantins-Araguaia, e fonte de renda para muitas pessoas que têm a pesca como única profissão. Além disso, é um importante recurso pesqueiro que move a economia dos municípios do nordeste do Pará, em especial a de Limoeiro do Ajuru, com média de produção estimada em 1.405 toneladas ao ano.

O Mapará é um peixe da ordem Siluriforme de porte médio, pertencente à família sul-americana Pimelodidae, que possuem uma ampla distribuição na América do Sul, incluindo a bacia amazônica, do Prata, Orinoco e águas costeiras do Pará (foz do Amazonas) até o Suriname. São peixes reofílicos, pois dependem da correnteza do ambiente natural para realizar suas funções reprodutivas (CARVALHO, 1980, p.545).

Essas espécies apresentam intensa atividade reprodutiva nos períodos mais chuvosos da região, cujo aumento do volume de água e maior velocidade de corrente do rio Tocantins proporciona cenário ideal para sua reprodução (COSTA et. al., 2010, p.166; FERREIRA et. al., 2016, p.88). Diferem dos siluriformes em geral, quanto ao hábito alimentar e localização na coluna d'água, pois enquanto a maioria é demersal e carnívoro, os Hypophthalmus são estritamente pelágicos e planctófagos (CARVALHO, 1980, p.553).

$\mathrm{Na}$ região do baixo Tocantins, especificamente na microrregião de Cametá, que engloba os municípios de Limoeiro do Ajuru, Cametá, Mocajuba e Baião, entre os anos de 2000 a 2005, foram capturados, cerca de 11.224 toneladas de pescados, sendo que $28 \%$ da captura foram de Mapará (MÉRONA et. al., 2010, p.86). Porém, nos últimos anos o quantitativo de pescado de Mapará tem diminuído consideravelmente.

No tocante a Educação Ambiental, esta emerge, exatamente, da complexidade socioambiental como um potencial ideológico e prático para mudanças de hábitos e atitudes nas relações com o meio ambiente e seus recursos, que pode contribuir significativamente para o processo de construção de uma sociedade pautada por novos patamares civilizatórios e societários distintos dos atuais, na qual a sustentabilidade da vida, a atuação política consciente e a construção de uma ética que se afirme como ecológica sejam seu cerne (LOUREIRO, et. al., 2002, p.69).

Em um contexto de políticas públicas integradas, a Educação Ambiental se apresenta como um instrumento mediador de interesses comuns à sociedade, levando em consideração a relação simétrica com o meio e seus recursos, como na resolução de conflitos socioambientais, sobretudo pelo seu caráter transformador.

Portanto, este artigo tem como objetivo analisar as implicações 
Limoeiro do Ajuru-PA, como fator condicionante para a redução do estoque pesqueiro da espécie Mapará, e propõe a concepção crítica da Educação Ambiental como possibilidade de reconstruir novos hábitos e atitudes sociais, cuja relação homem natureza tenha como cerne o respeito, a sinergia, o equilíbrio e, sobretudo, o uso sustentável dos recursos naturais.

Para tanto, de acordo com a concepção de Marconi e Lakatos (2003, p.83) que apontam o problema como definição para a abordagem teórica e os métodos a serem empregados na pesquisa. Considerou-se a complexidade da temática abordada e convencionou-se a adotar para este trabalho a interdisciplinaridade como fundamentação teórica metodológica, por proporcionar um olhar holístico na relação homem e natureza.

A interdisciplinaridade, enquanto pressuposto da $E A$, não é um princípio epistêmico que legitima determinados saberes e relações de hierarquia entre as ciências, nem um método único para articular conhecimentos capazes de produzir uma "metaciência". Constitui-se numa prática intersubjetiva que associa conhecimentos científicos e não-científicos relacionando o intuitivo, o cognitivo e o sensorial, buscando a construção de objetos de conhecimentos que se abram para novas concepções e compreensões do mundo e para a constituição do sujeito integral (COSTA et al., 2013, P.14).

Além dessa perspectiva de abordagem, este artigo se estruturou levando em consideração um levantamento bibliográfico e uma leitura minuciosa dos autores e legislações que discutem a Educação Ambiental de maneira transversal; em uma atividade de campo que proporcionou observações in loco e levantamento de informações preponderantes, por meio de entrevistas semiestruturadas com pescadores; em uma visita ao BPA para maiores informações sobre sua atuação no combate a pesca predatória no município de Limoeiro do Ajuru.

\section{Fundamentação teórica, aspectos legais e mecanismos de governança ambiental}

As populações pesqueiras têm por pilares de conhecimento os saberes da tradição que vão se adequando aos seus meios disponíveis, esses saberes não-científicos ligados às populações tradicionais envolvem relações estreitas entre o homem e a natureza, permeados em relações de ordens pontuais e místicas, são conhecimentos transmitidos das gerações mais experientes para as mais jovens, principalmente pela oralidade e pelas práticas do cotidiano (MORAES, 2007, apud MORAES, 2016, p.80).

A Política Nacional de Desenvolvimento Sustentável dos Povos e Comunidades Tradicionais (PNPCT) foi instituída em 2007, por meio do Decreto Federal no 6.040. A PNPCT é uma ação do Governo Federal que busca promover o desenvolvimento sustentável dos povos e comunidades tradicionais, com ênfase no conhecimento, fortalecimento e garantia dos seus direitos territoriais, sociais, ambientais, econômicos e culturais, com respeito e 
valorização à sua identidade, suas formas de organização e suas instituições (OLIVEIRA et al., 2016, p.101).

A pesca, o extrativismo vegetal, a agricultura, a pecuária extensiva são algumas das principais atividades de subsistência de grande parte desses grupos, garantindo parte de sua alimentação com produtos de suas terras, rios e mares (OLIVEIRA et al., 2016, p.104).

Para Diegues (2007, p.2) uma das características básicas das populações tradicionais é o fato de viverem em áreas rurais onde a dependência do mundo natural, de seus ciclos e de seus produtos é fundamental para a produção e reprodução de seu modo de vida. Uma grande parte delas vive à beira dos rios, lagos, igarapés e à beira-mar. As utilizações dos recursos naturais por essas comunidades dão identidades aos territórios e criam relações intrínsecas ao seu modo de viver, constituindo culturas singulares.

Entende-se por pesca, toda operação, ação ou ato tendente a extrair, colher, apanhar, apreender ou capturar recursos pesqueiros (Lei Federal no 11.959/2009). Todavia, este ato de pescar pode assumir características predatórias com grandes consequências negativas ao meio ambiente e a sociedade.

Em escala nacional, o Brasil apresenta dois importantes amparos legais que normatizam a atividade pesqueira em seu território. A Lei Federal no 11.959/2009 que institui a Política Nacional de Desenvolvimento Sustentável da Aquicultura e da Pesca e normatiza as modalidades de pesca, pescador, e principalmente, classifica instrumentos de pesca e períodos específicos considerados proibidos na utilização dos recursos pesqueiros. A Lei Federal no 9.605/1998 (Lei de Crimes Ambientais) que dispõe sobre as sanções penais e administrativas derivadas de condutas e atividades lesivas ao meio ambiente (SILVA JÚNIOR, et al., 2015, p.187).

Analisando brevemente a lei de crimes ambientais, verifica-se em seu Art. 34 o período no qual a pesca é proibida, assim como os petrechos que não podem ser utilizados na atividade pesqueira.

Art. 34. Pescar em período no qual a pesca seja proibida ou em lugares interditados por órgão competente:

Pena - detenção de um ano a três anos ou multa, ou ambas as penas cumulativamente.

I - Pescar espécies que devam ser preservadas ou espécimes com tamanhos inferiores aos permitidos;

II - Pescar quantidades superiores às permitidas, ou mediante a utilização de aparelhos, petrechos, técnicas e métodos não permitidos; 
Política Pesqueira e Aquícola no Estado, regulando as atividades de fomento, desenvolvimento e gestão ambiental dos recursos pesqueiros e da aquicultura e dá outras providências.

O Estado do Pará apresenta ainda sua Política de Meio Ambiente (Lei no 5.887/1995) que ampara sua atuação no campo da fiscalização ambiental (Art. 110 e 111), como mecanismo de comando e controle, bem como de programas voltados para a prevenção primária no viés da Educação Ambiental (Art. 87) com vistas a construção do uso racional dos recursos naturais.

O combate à pesca predatória no Estado do Pará é realizado por órgãos federais (Instituto Brasileiro do Meio Ambiente e dos Recursos Naturais Renováveis - IBAMA e Instituto Chico Mendes de Conservação da Biodiversidade - ICMBIO) quando os rios são nacionais, ou seja, ultrapassam limites territoriais estaduais e/ou em áreas de proteção ambiental; por órgãos estaduais (Secretaria de Estado de Meio Ambiente e Sustentabilidade SEMAS) quando os rios estão nos limites territoriais do Pará; por órgãos do poder público municipal (secretarias municipais de meio ambiente) que fiscalizam os limites de seu território ou de maneira integrada.

Essas fiscalizações contam com a participação do Batalhão de Polícia Ambiental - BPA, Unidade especializada da Polícia Militar do Pará, que garante a segurança de seus agentes, auxilia tecnicamente no planejamento e execução das operações de fiscalização ambiental, além de realizar o policiamento ostensivo em todo o Estado, por meio de suas ações.

Acrescenta-se a esses arcabouços legais, a mobilização das comunidades pesqueiras de Limoeiro do Ajuru, por meio dos Acordos de Pesca, espécie de regras, que os usuários estabelecem em comum acordo para salvaguardar os recursos pesqueiros, nos limites territoriais do referido município, durante o período do defeso.

Vilhena (2017, p.103) define os acordos de pesca como um conjunto de normas criadas pela comunidade usuária dos recursos pesqueiros de uma determinada região, com o auxílio e apoio de órgãos governamentais, que ajudam na fiscalização e controle da atividade pesqueira, com o intuito de garantir a produtividade pesqueira em áreas ameaçadas.

A Instrução Normativa no 29 de 31 de dezembro de 2002 do Instituto Brasileiro do Meio Ambiente e dos Recursos Naturais Renováveis - IBAMA, o define como:

O conjunto de medidas específicas decorrentes de tratados consensuais entre os diversos usuários e o órgão gestor dos recursos pesqueiros em uma área definida geograficamente como objetivo ordenar as práticas pesqueiras de forma participativa, considerando os interesses dos pescadores beneficiários (IN no 29/2002). 
Das medidas tomadas pelos Acordos de Pesca no município de Limoeiro do Ajuru, destaca-se a proibição da pesca no período do defeso; a proibição de malhadeiras com malha em desacordo com a legislação, o uso do puçá; a limitação da temporada de captura dos peixes, dando tempo para a recomposição dos cardumes, pois a busca intensa dificulta a captura dos peixes, uma vez que estes ficam escassos; a interrupção temporária da pesca quando a oferta dos pescados sobressai a da procura e a proibição de pescadores de outros municípios, que utilizam apetrechos de pesca em desacordo com os previstos pelas comunidades.

Para Santos (2004, p.23), o êxito dos acordos de pesca está intimamente ligado à sua propagação em escala regional, pois é necessário que moradores de rios e bacias hidrográficas vizinhas também elaborem seus acordos de pesca. Isto é fundamental devido à mobilidade dos peixes, que findam por serem capturados em áreas onde não vigoram os acordos de pesca, não permitindo assim que os peixes atinjam a idade adulta, considerada ideal para a captura. Daí a importância de os acordos de pesca serem disseminados em outras regiões e outros municípios.

Os resultados positivos dos Acordos de Pesca já constituídos têm motivado pescadores de outras comunidades do município a criarem seus Acordos. Atualmente existem 14 Acordos de Pesca no município de Limoeiro do Ajuru, que de maneira direta contribuem com a manutenção dos estoques pesqueiros do Mapará, beneficiando centenas de famílias que tem a pesca como única fonte de recursos (Tabela 1).

Tabela 1: Identificação dos Acordos de Pesca existente no Município de Limoeiro do Ajuru.

\begin{tabular}{ll}
\hline № & \multicolumn{1}{c}{ NOME } \\
\hline 01 & Acordo de Pesca da Amorosa \\
02 & Acordo de Pesca Reserva do Meio \\
03 & Acordo de Pesca da Prainha \\
04 & Acordo de Pesca do Rio Cardoso \\
05 & Acordo de Pesca do Piquiatuba \\
06 & Acordo de Pesca do Mocons \\
07 & Acordo de Pesca do Tatuoca \\
08 & Acordo de Pesca do Turussú \\
09 & Acordo de Pesca do Tucumanduba \\
10 & Acordo de Pesca do Rio Teobaldo \\
11 & Acordo de Pesca da llha Saracá \\
12 & Acordo de Pesca da llha Araraim \\
13 & Acordo de Pesca do Pautinga \\
14 & Acordo de Pesca do Capinal
\end{tabular}

Fonte: Conselho Municipal de Pesca de Limoeiro do Ajuru/PA (2018). 
Todavia, nem todos os pescadores do município concordam com as normas impostas pelos Acordos de Pesca, existe ainda forte resistência em aderir a essa nova dinâmica de uso do recurso pesqueiro, gerando conflitos locais que acabam desgastando o fortalecimento desses acordos.

\section{Educação Ambiental}

No que tange a Educação Ambiental, como instrumento preventivo de gestão integrada que possibilita maior racionalidade no uso dos recursos naturais, observa-se na Política Nacional (Lei no 9.795/1999) que sua atuação não está restrita somente ao ambiente escolar de maneira formal, abrange também outros níveis e modalidades do processo educativo, incluindo seu caráter não-formal.

A Amazônia retrata uma variedade de linguagens, a multiplicidade de culturas e riqueza biológica e cultural diversas, construindo uma diversidade multicultural importante e deve ser considerada, quando se analisam as formas de ser, estar, fazer e conviver nessa região.

A Amazônia não pode ser compreendida de forma homogeneizada, uma vez que possui realidades sociais e educacionais diversas, que compõem a complexa sociodiversidade amazônica, na qual a pluralidade cultural convive com a exuberância natural e biológica da região, marcada por matas verdejantes e rios caudalosos (LOUREIRO, 2009, p.12).

Segundo Silva Júnior (2018, p.71) a Educação Ambiental centralizada em suas diversas vertentes, sobretudo em sua concepção crítica, transformadora e emancipatória, se apresenta como uma proposta importante para uma nova racionalidade capaz de empreender novos caminhos para a busca da sustentabilidade, cujo seu campo de atuação abrange não somente a abordagem sobre as forma de degradação ambiental, mas, sobretudo no campo do entendimento sistêmico e da conscientização crítica que possibilita conduzir o homem à transformação de suas próprias realidades.

Loureiro (2003, p.12) fortalece essa concepção e a define como:

Uma prática social cujo fim é o aprimoramento humano naquilo que pode ser aprendido e recriado a partir dos diferentes saberes existentes em uma cultura, de acordo com as necessidades e exigências de uma sociedade. Atua, portanto, sobre a vida humana em dois sentidos: (1) desenvolvimento da produção social como cultura, mesmo dos meios instrumentais e tecnológicos de atuação no ambiente; (2) construção e reprodução dos valores culturais (LOUREIRO et al., 2003, p. 12).

A educação é para muitos especialistas um processo complexo de diversidade pelo qual a sociedade deve seguir para construir e reconstruir modos de vida sustentáveis. É necessário centralizar o indivíduo sobre suas 
potencialidades que permite transformar, compreender, questionar, identificarse e despertar sua interação com o meio.

Destacam-se neste contexto, os trabalhos pautados nessa concepção de Educação Ambiental crítica, transformadora e emancipatória (LOUREIRO, 2012; JACOBI, 2013; GUIMARÃES, 2004), a qual amplia as discussões ambientais para o campo da reflexão permanente, abordando as formas de constituição das relações comportamentais da sociedade, dialogando com a capacidade de alterar a realidade a que está inserido e redefinindo seus costumes e hábitos em relação ao espaço natural.

Diante disso, a Educação Ambiental visa uma mudança de valores e atitudes, através de uma reflexão/ação crítica de todos os cidadãos face aos problemas ambientais. Esta mudança aponta para a construção da cidadania, o resgate da dignidade e o reconhecimento do ser humano como sujeito e agente transformador da realidade em que se insere. O termo "ambiental" contribui para a compreensão do ser humano enquanto "elemento central e indissociável do ambiente" (LOUREIRO, 1997, p. 150).

A Educação Ambiental é, portanto, um viés interessante nesse contexto de transformação social, por mais simples que seja a abordagem sobre a temática, quando há o empoderamento de suas potencialidades a sociedade começa a agir em busca de transformar seus hábitos e melhorar as condições dos espaços vividos, com efeitos extremamente positivos e agregadores (SILVA JÚNIOR, 2018, p.73).

O entendimento da complexidade ambiental é o ponto de partida para que as ações de Educação Ambiental sejam refletidas e enraizadas pela sociedade, e que, portanto, se relacione com essa complexidade sócio econômica e ambiental através da construção de uma racionalidade fazendo com que as assimetrias existentes na relação homem/natureza, fruto do capitalismo, sejam reduzidas ou extintas e o sujeito compreenda a sua humanidade e reconstrua sua cultura de natureza.

Para isso, é necessário desenvolver ações contínuas de Educação Ambiental, levando em consideração a realidade e o perfil social da população, a fim de produzir resultados, que de fato, possam reconstruir as culturas e hábitos sustentáveis, igualmente a concepção racional de relação com o meio ambiente (SILVA JÚNIOR, 2018, p.78).

\section{Caracterização da área de estudo}

O município de Limoeiro do Ajuru pertence à Mesorregião Nordeste Paraense, microrregião de Cametá, baixo Tocantins (Figura 1), apresenta uma área territorial de $1.490,17 \mathrm{~km}^{2}$ e população de 25.021 habitantes sendo que $75 \%$ destes residem na área rural do município (IBGE, 2010).

O município tem sua economia baseada principalmente no extrativismo vegetal, com base na extração de açaí e na pesca artesanal, sobretudo do Mapará. A pesca é a principal fonte de renda dos ribeirinhos entre os meses de 
março a outubro, época que ocorre a abertura da pesca. O Mapará (Hypophthalmus spp.) é o peixe símbolo da região, todavia, outras espécies de peixes também são encontradas e apreciadas pela população regional, como é o caso da Pescada branca (Plagioscion squamosissimus), Tainha (Mugil brasiliensis), Sarda (Pellona castelnaeana), Dourada (Brachyplatystoma flavicans) e outros.

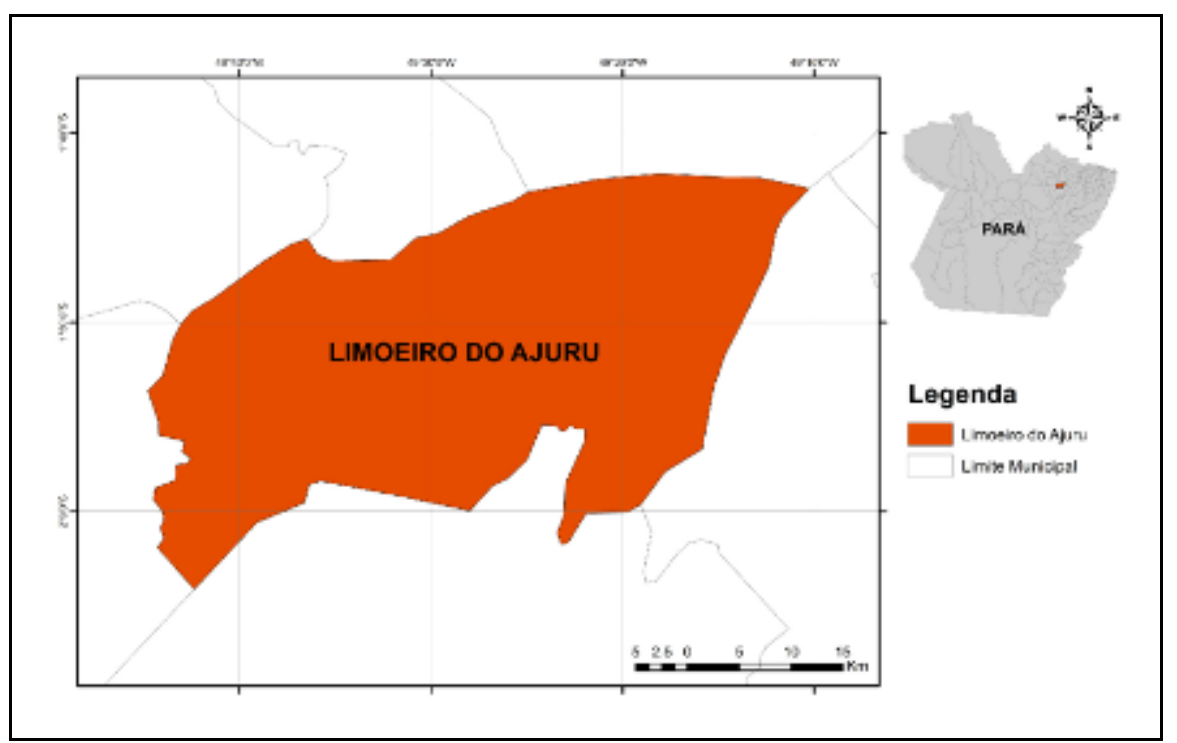

Figura 1: Mapa de localização da área de estudo. Fonte: Ricardo (2013).

O rio Tocantins nasce no Escudo Brasileiro Central e flui em direção ao norte sobre terrenos sedimentares por cerca de $2.500 \mathrm{~km}$ até desaguar no rio Pará, próximo à cidade de Belém/PA. Tem como principais afluentes, pela margem direita, os rios Manoel Alves do Sono e Manoel Alves da Natividade e, pela margem esquerda, os rios Araguaia, Santa Teresa e Itacaiúnas (ANA, 2002).

O clima na região do baixo Tocantins é do tipo quente úmido (IBGE, 1997), marcado por dois períodos bem definidos: o chuvoso, que se estende de dezembro a maio e precipitações atingindo valores entre $500-600 \mathrm{~mm} / \mathrm{mês}$ e o menos chuvoso, que ocorre de junho a novembro e precipitação da ordem de $30 \mathrm{~mm} / \mathrm{mês}$. Por ser uma área próxima à linha do Equador, as temperaturas são altas durante $\mathrm{o}$ ano inteiro, com médias mensais superiores a $24^{\circ} \mathrm{C}$ (FISCH; JANUÁRIO; SENNA, 1990; SANCHES; FISCH, 2005).

O rio Tocantins tem a água do tipo clara, segundo classificação de Sioli (1984), no entanto, próximo à confluência com o rio Araguaia passa pela Bacia Sedimentar do Meio Norte, uma formação bastante recente que, na época de chuva e cheia, contribui com muito sedimento para o baixo rio Tocantins, conferindo temporariamente às suas águas transparência entre 0,1 e $2 \mathrm{~m}$, com características de água branca com temperatura média de $29^{\circ} \mathrm{C}, \mathrm{pH}$ de 6,8 e oxigênio dissolvido de 4,3 mg/L (MÉRONA et al., 2010, p.26). 
A complexa morfogênese da bacia Araguaia-Tocantins favoreceu a evolução de uma assembleia de espécies únicas na Amazônia e que, antes da instalação da barragem da UHE Tucuruí, era representada por cerca de 300 espécies, 126 gêneros e 34 famílias, com predominância dos Characiformes, Siluriformes e Ciclídeos. No entanto, após 20 anos do fechamento da barragem, um inventário da ictiofauna no período 1999 - 2003 resultou na identificação de 13 ordens, 42 famílias e 217 espécies (SANTOS et al. apud MÉRONA et al., 2004, p.27).

\section{Pesca predatória do Mapará}

A pesca predatória do Mapará é cometida por pescadores do município de Limoeiro do Ajuru e de municípios circunvizinhos, como: Cametá, Muaná, Igarapé Miri, Abaetetuba, Mocajuba e outros, utilizando petrechos proibidos por lei, como: puçá, malhadeira e rede de bloqueio, sejam pelo fato de serem utilizados no período do defeso e/ou por suas características, sobretudo no que concerne ao tamanho de suas malhas.

Esses petrechos são comprados no mercado pesqueiro ou confeccionados pelos redeiros ${ }^{4}$ e são considerados predatórios, uma vez que capturam Maparás em tamanhos pequenos, inadequado para consumo, conhecidos na região como "fifites", além de outras espécies de peixes, e até mesmo botos, tanto o Branco (Inea geoffrensis), quanto o Tucuxi (Sotalia fluviatilis) que atraídos pelos cardumes de peixes, acabam se malhando e quase sempre são mortos por danificarem esses petrechos de pesca.

De acordo com Vilhena (2017, p.46-47), nos municípios do baixo Tocantins, os pescadores têm diminuído a malha das redes para garantir uma pesca mais rentável, porém, eles acabam capturando peixes ainda em maturação. Ação predatória esta, que não permite que esses filhotes consigam ao menos uma reprodução para que haja a reposição nos estoques dos recursos pesqueiros da região.

Um dos principais problemas da pesca predatória na nossa região é o uso de puçá e rede de bloqueio pelos pescadores de Limoeiro e municípios vizinhos, como Cametá e Igarapé- Miri. [...] é um problema por que a malha é muito pequena, e arrasta todos os tamanhos de Mapará e outras espécies também, inclusive, Botos que muitas vezes é morto pelo pescador (F. B. pescador do município de Limoeiro do Ajuru. Entrevista concedida em 15/03/2018).

${ }^{4}$ Pessoa que confecciona puçá e malhadeira de pesca.

Revbea, São Paulo, V. 14, No 1: 81-100, 2019. 
a) Malhadeira: constituídas por um conjunto de malhas de mica ou de nylon chamado de pano; pequenas peças de chumbo, denominadas chumbadas, que podem ou não ser colocadas na parte inferior do pano para manter o equilíbrio da malhadeira na água. Assim, para pescar parado nas mansas águas dos lagos, a malhadeira pode prescindir desse instrumento de equilíbrio, ao passo que nas águas turbulentas do Amazonas e Tocantins, as chumbadas tornam-se indispensáveis.

As boias, feitas principalmente de isopor, formam um sistema de sustentação da parte superior das redes próximo da lâmina d'água. Elas também funcionam como sinalizadores, pois muitos pescadores, inclusive, reconhecem a presença de determinados tipos de peixes na rede, pelo simples movimento de sua descida e subida à tona d'água. A corda é o instrumento que prende uma das extremidades superior da rede à popa da canoa, quando a pesca é feita em movimento.

Quando a pesca é parada em um determinado lugar, nas duas extremidades superiores, as cordas são amarradas em estacas, de modo que a rede fique relativamente esticada e presa. Verificou-se também que, para fixar as redes nas movimentadas águas do Amazonas e Tocantins, os pescadores utilizam poita de pedra sustentada por duas cordas amarradas nas extremidades inferiores da rede (DO CANTO, 2007, p.134).

b) Rede de bloqueio (rede aberta): A rede de bloqueio, chamada pelos ribeirinhos de "borqueio", é um petrecho de pesca que é construída manualmente. Os pescadores compram os panos de nylon, que variam de tamanho, em seguida unem uns aos outros, até atingir o tamanho desejável. Na parte superior do pano, é colocado o cabo, nele é inserida a cortiça para equilibrar e manter a rede na lâmina d'água. $\mathrm{Na}$ parte inferior do pano, é colocado outro cabo, nele é inserida a chumbada, para também equilibrar e fazer com que a rede fique esticada, quando jogada no rio.

Depois de todos esses procedimentos, a rede de bloqueio está pronta para ser usada. Geralmente uma rede pronta tem 450 metros de comprimento, e 18 metros de altura. A medida utilizada pelos ribeirinhos é a braça, nesse caso as medidas são, respectivamente, 250 e 10 braças. A rede de bloqueio é dividida entre dois $\operatorname{cascos}^{5}$ (MÉRONA et. al., 2010, p.71-72).

O processo de captura do Mapará, utilizando a rede de bloqueio tem suas peculiaridades, cujo saberes locais são preponderantes para o sucesso da captura dos cardumes. Além disso, a pesca com esse petrecho exige um número considerável de pescadores, cada um com suas atribuições.

Nesse sentido, o pescador-informante, responsável por localizar o cardume, observa, por exemplo, onde se concentram predadores naturais do Mapará, como boto-tucuxi (Sotalia sp.) e boto-branco (Inea geoffrensis), mergulhão (Phalacrocorax sp.) e gaivotas, ou mesmo, pelo próprio cheiro forte exalado pela espécie, popularmente chamado de "pitiú", em seguida, com o

\footnotetext{
${ }^{5}$ Pequena embarcação ribeirinha, também chamada de canoa.
}

Revbea, São Paulo, V. 14, № 1: 81-100, 2019.

revista brasileira educação ambiental 
auxílio de uma vara feita do cerne de uma palmeira denominada paxiúba (Soccretea sp.), o pescador identifica o local e estima o tamanho do cardume e dos peixes que o formam.

Caso esses fatores favoreçam à pesca, a informação é transmitida ao pescador-chefe, que se desloca para dar início à segunda etapa. Nesta etapa, dois ou três taleiros ${ }^{6}$, acompanham o deslocamento do cardume, sondando periodicamente a profundidade do local. De acordo com o deslocamento do cardume, são dados sinais de orientação e posicionamento dos pescadores responsáveis pela mupunga ${ }^{7}$. Quando o cardume se encontra em local favorável, isto é, relativamente limpo e com cerca de menos de $9 \mathrm{~m}$ de profundidade, é dado o sinal para abertura da rede e da mupunga.

Após concluído o cerco do cardume, a rede é fixada com uma âncora, fazendo com que uma das redes se projete contra a outra pela força da correnteza. Quando as redes estão próximas, alguns pescadores mergulham e passam a chumbada de uma das redes sob a outra, de modo a aprisionar o cardume em uma das redes. Na última etapa, parte da rede é colhida, concentrando o cardume, facilitando a despesca, que pode ser realizada com uma redinha ou com paneiros de palha (MÉRONA et al., 2010, p.71-72).

c) Puçá: possui características similares a rede de bloqueio, distinguindo-se pela altura, enquanto a altura da rede aberta é de 10 braças (18 metros), a do puçá passa das 20 braças de altura (mais de 36 metros de altura), sendo que nos lugares mais rasos, a rede de puçá se arrasta pelo fundo do rio, capturando tudo o que tiver no seu caminho, também pelo material de confecção, que é mais resistente, o que o torna bem mais caro. $O$ processo de captura do Mapará assume as mesmas características da rede de bloqueio (MÉRONA et al., 2010, p.71-72).

Conforme Instrução Normativa Interministerial MPA/MMA no 13/2011, que estabelece diretrizes e normas a serem cumpridas pelos usuários para a garantia do estoque pesqueiro, o período de defeso na bacia hidrográfica do rio Tocantins vai de 10 de novembro a 28 de fevereiro. Não significa dizer que durante este período de reprodução das espécies a pesca é totalmente proibida, há a previsão legal que ampara a pesca de subsistência, cujo pescador pode capturar até $5 \mathrm{~kg}$ (cinco quilos) mais um exemplar, justamente para garantir a alimentação de sua família.

[...] Art. 10. Limita a quantidade máxima de captura, por pescador, a $5 \mathrm{~kg}$ cinco quilos mais um exemplar, por ato de fiscalização, para pesca de subsistência, respeitados os tamanhos mínimos de captura estabelecidos em legislação vigente (INI MPA/MMA no 13/2011).

${ }^{6}$ Pescador que identifica e acompanha o cardume de Mapará, por meio da vara feita da Paxiúba.

7 Processo de pesca em que se bate na água de um rio com uma vara, ou com a mão, para afugentar o peixe na direção desejada.

Revbea, São Paulo, V. 14, № 1: 81-100, 2019. 
Todavia, o desrespeito ao período do defeso é uma das infrações ambientais comuns no município de Limoeiro do Ajuru, identificadas pelos pescadores que desenvolvem suas atividades de maneira legal e sustentável, bem como pelos órgãos de fiscalização ambiental, por meio das apreensões e autos de infrações.

Para o pescador M. V., com mais de 28 anos de profissão, a utilização desses petrechos de pesca e a precariedade da fiscalização estão levando a escassez do Mapará, preocupando a todos que dependem da pesca para subsistência.

A hidrelétrica de Tucuruí afetou as "cucuias" (poços) usada pelo Mapará pra sua desova, que com o passar dos anos foram aterradas. Mas, o que me preocupa hoje é a pesca com essas redes que arrastam tudo, não respeitam o tamanho do peixe [...].Pior do que isso é saber que muitos desses pescadores são de Limoeiro e fazem esses arrastão no período do defeso, onde o peixe tá ovado, isso me deixa muito triste e preocupado, por que muita gente depende desse rio pra sobreviver e eles só pensam no agora, nem quer saber do amanhã. Pior que a gente não pode fazer nada, por que eles anda armado e ameaça a gente ou xinga a gente quando a gente vai chamar atenção deles.

Segundo os pescadores, os Acordos de Pesca, dentro de suas limitações, vêm apresentando resultados positivos no que tange à conservação do Mapará, sobretudo quando o BPA realiza o policiamento ambiental no município durante o período do defeso.

Todavia, as despesas com diárias dos policiais ambientais que realizam o policiamento preventivo e repressivo durante o defeso, são custeadas pelos Acordos de Pesca em parceria com o poder público local, situação que nos últimos anos deixou de existir por alegarem dificuldades financeiras. Para garantir a presença do BPA no período do Defeso dos anos de 2017 e 2018, membros da Prefeitura e dos Acordos de Pesca solicitaram apoio a SEMAS e a PMPA, no entanto, não foram atendidos, sobre a justificativa do prazo da solicitação, que precisa ser com bastante antecedência para que seja realizado o planejamento financeiro, bem como pela elevada demanda de solicitações das referidas instituições.

Ficou acertado que o BPA disponibilizaria 01 (uma) lancha, combustível e a cada mês uma equipe contendo 04 (quatro) policiais e que a contrapartida da prefeitura em parceria com os Acordos de Pesca, seria no sentido de custear as despesas de diárias dos policiais. Nos primeiros anos este acordo ocorreu tudo bem, no entanto em 2016, quando eles atrasaram e deixaram de pagar as últimas guarnições que realizaram suas atividades naquele município, este acordo foi suspenso. 
(Tenente Coronel Fernando Bilóia - Comandante do BPA. Entrevista concedida em 03/04/2018).

Por este fato, pescadores relatam que em 2017 houve um aumento considerável dos casos de pesca predatória no município, cujo reflexo foi sentido na produção do pescado, que ficou muito abaixo das médias anteriores. Coincidentemente, neste ano não houve a fiscalização ambiental realizada pelo BPA, motivo que pode justificar o aumento dos casos de pesca predatória e consequentemente a redução do pescado.

Segundo o presidente do Acordo de Pesca Reserva do Meio, Sr. D. N. V., a presença dos policiais ambientais, inibem as ações degradadoras e contribuem bastante para a reprodução das espécies.

O Gráfico 1 apresenta oscilação decrescente das aberturas da pesca após os períodos do defeso, durante uma periodização que compreende os anos de 2009 a 2017. Nota-se que durante este período a produção do pescado só reduziu, culminando com os dados de 2017 onde registrou o pior resultado da pesca do Mapará.

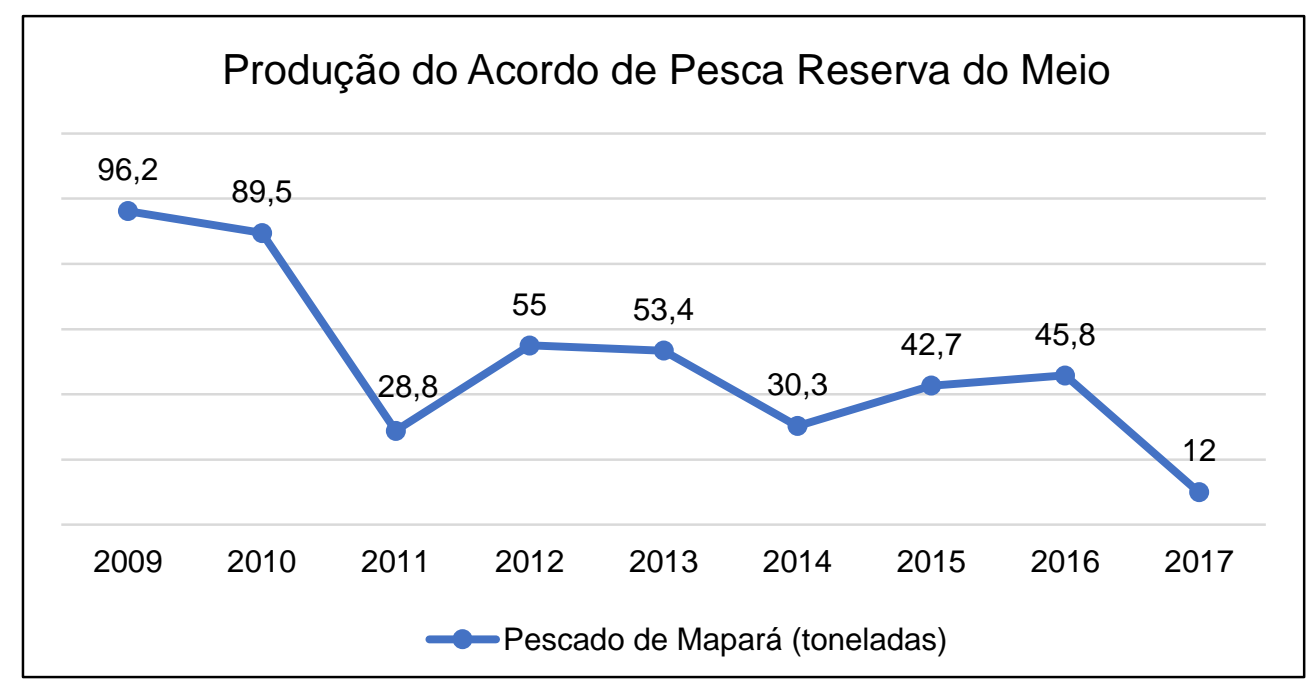

Gráfico 1: Produção de pescado do Acordo de Pesca Reserva do Meio (2009 a 2017).

Fonte: Elaboração própria a partir de dados do Acordo de Pesca Reserva do Meio (2018).

Ressalta-se que toda a produção do pescado é dividida em partes iguais entre os redeiros e os Acordos de Pesca, os dados apresentados na Tabela 2, refere-se somente a parte que cabe ao Acordo. 
Tabela 2: Pescado de Mapará contabilizada no período de 2009 a 2017, pelo Acordo de Pesca Reserva do Meio, município de Limoeiro do Ajuru-PA.

\begin{tabular}{cc}
\hline Ano & Quantidade de Mapará \\
\hline 2009 & 96,2 toneladas \\
2010 & 89,5 toneladas \\
2011 & 28,8 toneladas \\
2012 & 55 toneladas \\
2013 & 53,4 toneladas \\
2014 & 30,3 toneladas \\
2015 & 42,7 toneladas \\
2016 & 45,8 toneladas \\
2017 & 12 toneladas \\
\hline Total & Fonte: Acordo de Pesca Reserva do Meio $(2018)$ \\
\hline
\end{tabular}

Esses dados apontam uma preocupante situação, pois ocorrem em todos os outros Acordos de Pesca, cuja suas produções também declinaram nos últimos nove anos. Para os pescadores essa redução ocorre pela pesca predatória, sobretudo no período do defeso, pela ausência de fiscalização ambiental e pela falta de consciência/educação da população.

É fato que as medidas tomadas pelos Acordos de Pesca contribuem para a conservação das espécies de Mapará, todavia, são incipientes e necessitam de maior participação do poder público local e estadual, seja através das ações de comando e controle integradas ou por atividades de prevenção primária, no viés da Educação Ambiental crítica que possibilita transformações sociais.

\section{Educação Ambiental como instrumento de gestão para preservação do Mapará}

A Educação Ambiental, através de suas potencialidades e seu caráter transversal e interdisciplinar, nos permite discutir e empoderar-se dessas complexidades sistêmicas que envolvem a relação homem e meio ambiente e compreender a dinâmica comportamental contemporânea da sociedade e transformá-la, possibilitando a redução das lacunas existentes entre homem e natureza, bem como a retomada de novas culturas, cujo respeito e responsabilidade com o meio ambiente, em sua definição macro, seja considerada (SILVA JÚNIOR, 2018, p.26-27).

Suas potencialidades consistem simplificadamente em um processo permanente, cotidiano e coletivo pelo qual o sujeito constrói suas ações, refletindo, agindo e transformando a realidade de vida. É necessário conhecer a dinâmica do ambiente, pessoas, modos de vidas, vontades, percepção das 
questões ambientais para a partir de então orientar suas ações em solucionar, satisfazer e sobretudo responsabilizar.

Com esse propósito, membros desse artigo que trabalham na Secretaria Municipal de Meio Ambiente de Limoeiro do Ajuru, de maneira articulada, vêm desenvolvendo ações de promoção desse entendimento, seja por meio de debates com a população ou por meio de ações concretas. Neste contexto, cabe destacar a I Mesa Redonda Ambiental de Limoeiro do Ajuru, cujas discussões abordaram a Gestão ambiental no município, e o ato de Educação Ambiental junto aos diversos usuários das praias existentes no município, que consistiu em panfletagem, conversas e coleta de resíduos sólidos das praias durante o mês de julho/2018, período que aumenta a demanda de uso das praias como alternativa de lazer (Figura 2).
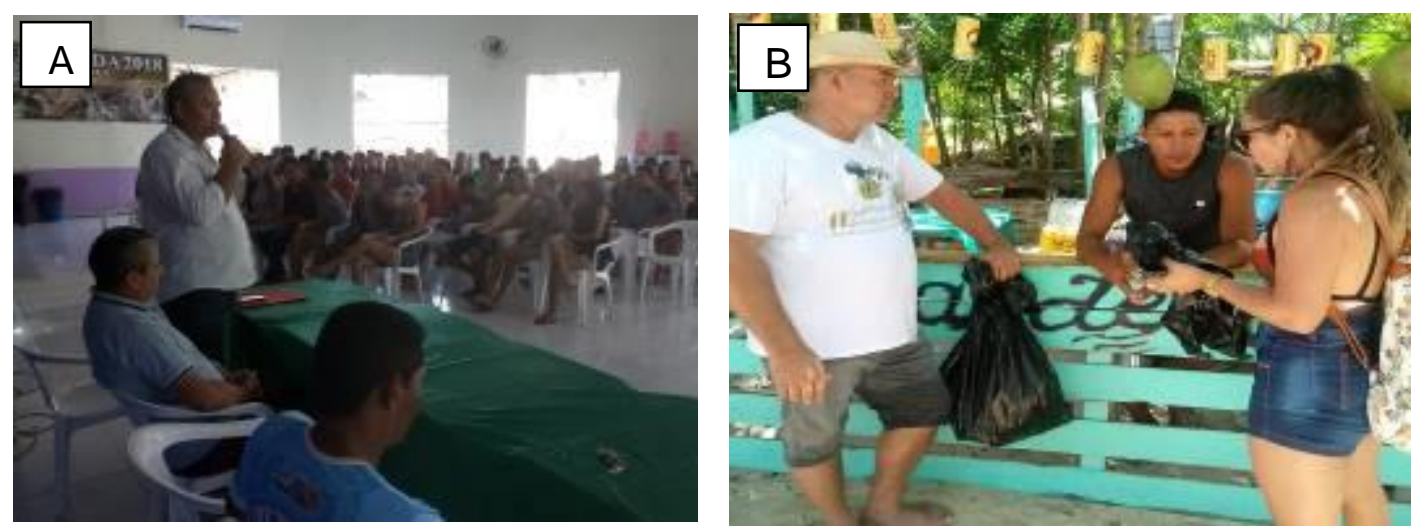

Figura 2: Ações desenvolvidas em parceria com o poder público local. (A) Apresentando e debatendo os instrumentos de Gestão Ambiental junto as comunidades do município de Limoeiro do Ajuru, incluindo as discussões sobre a pesca do Mapará. (B) ação de Educação Ambiental nas praias do município. Fonte: Autores (2018).

Dessa maneira acredita-se que a Educação Ambiental pode se constituir em elemento fundamental no combate ao modelo de uso degradante dos recursos pesqueiros do município de Limoeiro do Ajuru/PA, justamente por possibilitar transformação humana, promover a integração do indivíduo com o meio ambiente, a conscientização e a disseminação de conhecimentos, saberes, valores, em prol de uma sociedade sustentável.

Em linhas gerais, a Educação Ambiental se configura como uma proposta interessante na preservação dos recursos pesqueiros do município de Limoeiro do Ajuru, não como um instrumento de resolução dos problemas enfrentados pela comunidade, mas por suas potencialidades em construir novos hábitos e comportamentos que sensibiliza, transforma e emancipa o cidadão de culturas sistematicamente errôneas. Instigando-os a refletir, agir e ser críticos das relações sociais, econômicas, cultural e, sobretudo ambiental, possibilitando a construção de uma sensibilização e/ou racionalidade ambiental que contribuirá com a sustentabilidade do meio ambiente e de seus recursos, tal como na participação de tomadas de decisão do poder público, contribuindo diretamente com a sociedade. 


\section{Conclusões}

Diante dos resultados apresentados e discutidos, conclui-se temporariamente, que há uma necessidade premente de pensar projetos integrados de gestão ambiental, principalmente no que concerne ao uso dos recursos pesqueiros do município de Limoeiro do Ajuru-PA, envolvendo as esferas de governo, sobretudo o poder público local em conjunto com a sociedade, com a finalidade de garantir a sustentabilidade dos recursos naturais, fortalecendo e otimizando iniciativas positivas oriundas da sociedade, como é o caso dos Acordos de Pesca e inserir neste contexto ações permanentes de Educação Ambiental.

Daí o apontamento da Educação Ambiental como instrumento aliado da gestão ambiental em suas múltiplas vertentes, não como medida paliativa, comumente adotada pelo poder público, mas como incorporação de um projeto político pedagógico a longo prazo que busca contemplar a sociedade do município em questão, especialmente a comunidade pesqueira que precisa empoderar-se das implicações da pesca predatória e por conseguinte repensar suas atitudes, adotando novos comportamentos que se aliam à sustentabilidade.

Portanto, essa Educação Ambiental não tem que ser vista como um instrumento de resolução dos problemas vivenciados pelo município de Limoeiro do Ajuru, mas como um mecanismo aliado a outras políticas públicas que proporciona o fortalecimento da gestão ambiental em sua fase preventiva.

Deste modo, os eventos realizados pelo poder público em parceria com membros deste artigo demonstraram aspectos motivacionais por parte da população e precisam ser contínuos, (re)construindo hábitos que primam pela conservação do meio ambiente, sob a égide da conscientização de suas ações em relação ao espaço explorado e vivido, proporcionando qualidade de vida a todos e relações de interesses comuns simétricas com o meio ambiente e seus recursos naturais, tal como na redução/resolução dos conflitos prementes.

Para tanto, faz-se necessário esforços para inserir no cronograma anual da SEMAS, ações de fiscalização ambiental no município, em especial no período do defeso, assim como a permanência do BPA durante todo o período, tendo suas despesas pagas pela SEMAS; oferecer denúncias de caso de pesca predatória junto a Superintendência do Ministério Público local, a fim de intermediar com os órgãos ambientais ações de combate aos ilícitos ambientais; fortalecer e aperfeiçoar as propostas de Acordos de Pesca, por meio de legislação ambiental municipal, assim como seu reconhecimento pelo IBAMA através de INI e desenvolver um programa de Educação Ambiental, em sua vertente crítica, transformadora e emancipatória que possibilita sensibilizações da problemática ambiental e transformações sociais positivas na relação homem/natureza, cujo uso racional dos recursos pesqueiros seria seu cerne. 
Por fim, à luz do que foi apresentado como possibilidades de minimização e mitigação da pesca predatória sobre a espécie do Mapará, no município de Limoeiro do Ajuru, cabe salientar a participação propositiva da sociedade organizada, no sentido de contribuir de fato com a gestão ambiental local e, sobretudo, com sua qualidade de vida. Seja cobrando atitudes das autoridades competentes e/ou envolverem-se nos arranjos organizacionais da gestão ambiental, sobretudo por meio da Educação Ambiental que precisa estar atrelada aos anseios do contexto social local, ou seja, não tem que ser uma imposição, tão pouco cópia de modelo ou modismo, mas deve ter suas raízes postuladas pelos atores sociais inseridos neste contexto, com a finalidade de melhoria socioambiental.

\section{Referências}

AGÊNCIA NACIONAL DE ÁGUAS (ANA). Bacia do Tocantins. Disponível em: <http://www3.ana.gov.brAcesso> em: 16 jun 2018.

BRASIL. Lei Federal o 9.605, de 12 de fevereiro de 1998. Dispõe sobre as sanções penais e administrativas derivadas de condutas e atividades lesivas ao meio ambiente, e dá outras providências. Brasil - DF, 1998.

BRASIL. Lei Federal o 9.795 de 27 de abril de 1999. Dispõe sobre a Política Nacional de Educação Ambiental, Brasília - DF, 1999.

BRASIL. Lei Federal no 11.959 de 29 de julho de 2009. Dispõe sobre a Política Nacional de Desenvolvimento Sustentável da Aquicultura e da Pesca, Brasília - DF, 2009.

CARVALHO, F.M. Alimentação de Mapará (Hypophthalmusedentatus, Spix 1829) do Lago Castanho, Amazonas (Siluriformes, Hypophthalmidae). Acta Amazonica, v.10, n.3, pp.545-555, 1980.

COSTA, T.V.; OSHIRO, L.M.Y.; SILVA, E.C.S. O potencial do mapará Hypophthalmus spp. (Osteichthyes, Siluriformes) como uma espécie alternativa para a piscicultura na Amazônia. Bol. Inst. Pesca, São Paulo, v.36, n.3, pp.165-174, 2010.

COSTA, C.A.S.; LOUREIRO, C.F.B. Educação Ambiental crítica e interdisciplinaridade: a contribuição da dialética materialista na determinação conceitual. NUPEAT-IESA-UFG, v.3, n.1, Jan./Jun., 2013, p. 1-22.

DECRETO Lei oㅜ 2.020 de 24 de janeiro de 2006. Regulamenta a Lei oㅡ 6.713, de 25 de janeiro de 2005, que dispõe sobre a Política Pesqueira e Aquícola no Estado do Pará, regulando as atividades de fomento, desenvolvimento e gestão ambiental dos recursos pesqueiros e da aquicultura. D.O.E - PA, 25 jan. 2006.

DIEGUES, A.C. Água e cultura nas populações tradicionais brasileiras. São Paulo: NUPAUB-USP, 2007.

DO CANTO, O. Várzea e Varzeiros da Amazônia. Belém: MPEG, 2007. 
FERREIRA, L.C.; PONTE, S.C.S.; SILVA, Á.J.S.; ZACARDI, D.M. Distribuição de larvas de Hypophthalmus (Pimelodidae, Siluriformes) e sua relação com os fatores ambientais no baixo Amazonas, Pará. Rev. Bras. Eng. Pesca, v.9, n.2, pp.86-106, 2016.

FISCH, G.F.; JANUÁRIO, M.; SENNA, R.C. Impacto ecológico em Tucuruí (PA): Climatologia. Acta Amazônica, v. 20, n. 1, pp.49-60, 1990.

GUIMARÃES, M. (Ed). (2004). Educação Ambiental crítica. Identidades da Educação Ambiental brasileira. (1a ed.). Brasília: Ministério do Meio Ambiente.

INSTITUTO BRASILEIRO DE GEOGRAFIA E ESTATÍSTICA (IBGE). Recursos naturais e meio ambiente: uma visão do Brasil. 2. ed. Rio de Janeiro, 1997. 208 p.

INSTITUTO BRASILEIRO DE GEOGRAFIA E ESTATÍSTICA (IBGE)Contagem da população 2010 e histórico dos municípios do Pará. IBGE, Brasil, 2010. Disponível em: <https://cidades.ibge.gov.br/brasil/pa/limoeiro-doajuru/panorama>. Acesso: 11 jul. 2018.

INSTRUÇÃO NORMATIVA n ${ }^{\circ} 29$, de 31 de dezembro de 2002. Estabelece critérios de regulamentação de Acordos de Pesca. D.O.U. 21 jun. 2002.

ISNTRUÇÃO NORMATIVA INTERMINISTERIAL MPA/MMA no 13 de 25 de outubro de 2011. Estabelece normas gerais à pesca para bacia hidrográfica do rio Tocantins e período de defeso para as bacias hidrográficas dos rios Tocantins e Gurupi. D.O.U. 26 out. 2011.

LOUREIRO, C.F.B.; LAYRARGUES, P.P., CASTRO, R.S. Educação Ambiental: repensando o espaço da cidadania. 2.ed. São Paulo: Cortez, 2002.

LOUREIRO, C.F.B. A Educação Ambiental junto às classes populares: condições teóricas e práticas essenciais para uma ação transformadora. Cadernos Pedagógicos e Culturais, Niterói, v. 6, n. 1/ 2, jan./ dez. 1997.

LOUREIRO, C.F.B. Educação Ambiental e gestão participativa em unidades de conservação. Rio de Janeiro: Ebadi/Edições IBAMA, 2003.

LOUREIRO, C.F.B. Trajetória e fundamentos da Educação Ambiental. 3. ed. São Paulo: Cortez, 2009.

LOUREIRO, C.F.B. Pensamento complexo, dialética e Educação Ambiental. 2. ed. São Paulo: Cortez, 2012.

MARCONI, M.A.; LAKATOS, E.M. Fundamentos de Metodologia Científica. 5. ed. São Paulo: Atlas, 2003.

MÉRONA, B.; JURAS, A.A.; SANTOS, G.M.; CINTRA, I.H.A. Os peixes e a pesca no baixo Rio Tocantins: vinte anos depois da UHE Tucuruí. Brasília, 2010.

MORAES, S.C. Uma arqueologia dos saberes da pesca: Amazônia e Nordeste. Belém: EDUFPA, 2007.

revista brasileira educação ambiental 
MORAES, S.C. Conhecimentos tradicionais na pesca artesanal. Ateliê Geográfico, Goiânia-GO v. 5, n. 2, p. 88-105, 2011.

OLIVEIRA, O.C.; MORAES, S.C. Processos socioeconômicos e impactos sobre o uso da água em comunidades tradicionais na Amazônia: o caso da comunidade São Francisco do Iratapuru no estado do Amapá-AP. In: MORAES, S.C. (org.). Conhecimentos Tradicionais: discussões e desafios. Belém: NUMA/UFPA, 2016.

PARÁ. Lei Estadual no 6.713 de 25 de janeiro de 2005. Dispõe sobre a Política Pesqueira e Aqüícola no Estado do Pará, Belém - PA, 2005.

PARÁ. Lei Estadual no 5.887 de 09 de maio de 1995. Dispõe sobre a Política Estadual do Meio Ambiente, Belém - PA, 1995.

SANTOS, G.M.; MÉRONA, B.; JURAS, A.A.; JÉGU, M Peixes do baixo rio Tocantins: 20 anos depois da Usina Hidrelétrica de Tucuruí. Brasília: Eletronorte, 2004. 216p.

SANCHES, F.; FISCH, G.F. As possíveis alterações microclimáticas devido a formação do lago artificial da hidrelétrica de Tucuruí -PA. Acta Amazonica, v.35, n. 1, p. 41-50, 2005.

SILVA JÚNIOR, A.R.; CUTRIM CARVALHO, A. Pesca predatória na bacia hidrográfica do rio Peixe Boi no Pará: uma discussão sobre as suas implicações socioambientais. Pôster Meio ambiente. Anais do 4ํㅗํ Simpósio de Estudos e Pesquisas em Ciências Ambientais na Amazônia, Belém-PA, 2015.

SILVA JÚNIOR, A.R. Indicadores de vulnerabilidade, risco socioambiental e Educação Ambiental para prevenção e mitigação de desastre natural na bacia hidrográfica do Tucunduba, Belém-PA. Dissertação (Mestrado em Gestão de Risco e Desastres Naturais na Amazônia) - Instituto de Geociências, Universidade Federal do Pará, Belém, 2018.

VILHENA, J.R. Acordos de pesca na Amazônia: uma análise das experiências de manejo comunitário dos municípios do baixo Tocantins no estado do Pará. Anais do IX Encontro Nacional da Sociedade Brasileira de Economia Ecológica, Uberlândia, MG. 2017. 